\title{
Simulation Model for Borehole Heat Exchangers
}

\author{
Petri Hietaharju $^{1}$ Tobias Boström ${ }^{2}$ \\ ${ }^{1}$ Control Engineering, Faculty of Technology, University of Oulu, Finland, petri.hietaharju@oulu.fi \\ ${ }^{2}$ Department of Physics and Technology, UiT, The Arctic University of Norway, Norway, tobias .bostrom@uit. no
}

\begin{abstract}
Seasonal thermal energy storage (STES) offers a solution to address the mismatch between production and consumption by storing the produced excess heat for later use. Borehole heat exchangers (BHEs) are one of the sensible STES technologies. In this paper, a longterm simulation model for BHEs was developed. A finite line-source model for the heat transfer outside the borehole and a quasi-3D model for the heat transfer inside the borehole were applied in two region simulation approach. Fast Fourier transformation technique together with a cubic spline interpolation method were used for faster simulation time with time varying loads and longer simulation periods. The simulation method was validated using experimental data. Results showed that the simulation model is able to accurately model ground and fluid temperature evolution.
\end{abstract}

Keywords: ground heat exchangers, boreholes, modelling, simulation, validation

\section{Introduction}

As renewable energy is gaining popularity, the storage of the energy is becoming increasingly important. In many times, the energy production from renewable energy sources is not aligned with the energy consumption. This situation arises for example with solar energy and waste incineration sources in cold climate conditions. Thermal energy storage (TES) systems offer a solution to address this mismatch between production and consumption by storing the produced excess heat for later use (Alva et al., 2018). Long-term TES systems are called seasonal thermal energy storages (STES) and can be further categorized into sensible, latent and chemical heat storages (Xu et al., 2014). Different sensible STES systems have been implemented in many large-scale projects since the 1980s and it is considered the most mature and reliable technology compared with the other options (Xu et al., 2014). In this work, simulation model for borehole heat exchangers (BHEs) is presented and validated. The analytical approach enables fast simulation times and flexibility to incorporate the model for system level simulations in different TES applications.
BHEs are one of the sensible STES technologies. They are the most commonly applied technology in ground source heat pump systems whose use has been significantly increasing in recent years (Lund and Boyd, 2016). To design, construct and operate BHE systems, modelling is needed (Koohi-Fayegh and Rosen, 2013). Determining the temperature of the fluid inside the borehole is the main goal of BHE modelling. Based on the fluid temperature range, the size and number of boreholes can be determined. Models can also be used to estimate the temperature rise in the ground. For reliable results, it is important that BHE model is validated against actual measurements. In many cases, field tests are used for validation, but laboratory scale tests can provide more controlled and reliable testing environment (Beier et al., 2011).

For modelling purposes, the heat transfer in BHE is usually divided into two regions: heat transfer inside the borehole and heat transfer outside the borehole. Models for these two regions are then linked by the borehole wall temperature. Many numerical and analytical approaches to modelling both regions have been suggested (Yang et al., 2010; Li and Lai, 2015). Li and Lai (2015) argue that analytical methods can be more useful than numerical methods for advancing GHE technology. Although numerical methods can be more accurate than the analytical ones, they can also be computationally inefficient and not suitable for being directly incorporated into a design or energy analysis programs. Analytical models include assumptions and simplifications that slightly reduce the accuracy of the results. However, the calculation time is also reduced, making them more suitable for long-term simulations and the algorithms are usually straightforward to implement in simulation programs.

In this work, a long-term simulation model for BHEs is developed and then validated against two different laboratory scale experimental data sets. Analytical models for heat transfer inside and outside of the borehole are applied and methods to reduce the calculation time are employed. 


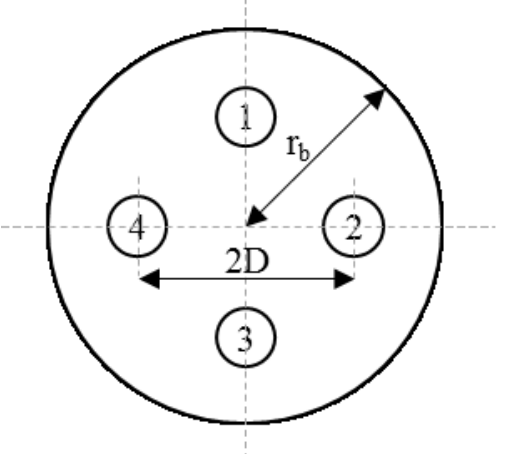

Figure 1. The cross section of a double U-tube borehole.

\section{Methods}

\subsection{Heat Transfer Inside Boreholes}

Zeng et al. (2003a; 2003b) presented a quasi-3D model for calculating the fluid temperature inside the borehole. Unlike the previous one- and two-dimensional models, this quasi-3D model takes into account the fluid temperature variation along the borehole depth. It is therefore a more accurate representation of the thermal process in the borehole heat exchanger. However, to keep the model concise and analytically manageable the convective heat flow in the grout and the ground in the axial direction is not considered.

Figure 1 shows the cross section of a borehole with a double U-tube configuration. The temperature excess in the four pipes of the U-tubes inside the borehole can be expressed as:

$$
\begin{aligned}
& T_{f 1}-T_{b}=R_{11} q_{1}+R_{12} q_{2}+R_{13} q_{3}+R_{14} q_{4} \\
& T_{f 2}-T_{b}=R_{21} q_{1}+R_{22} q_{2}+R_{23} q_{3}+R_{24} q_{4} \\
& T_{f 3}-T_{b}=R_{31} q_{1}+R_{32} q_{2}+R_{33} q_{3}+R_{34} q_{4} \\
& T_{f 4}-T_{b}=R_{41} q_{1}+R_{42} q_{2}+R_{43} q_{3}+R_{44} q_{4}
\end{aligned}
$$

where $T_{f 1}, T_{f 2}, T_{f 3}$ and $T_{f 4}$ are the fluid temperatures, $T_{b}$ is the borehole wall temperature, $q_{1}, q_{2}, q_{3}$ and $q_{4}$ are the heat fluxes per unit length, $R_{i i}(i=1,2,3,4)$ is the thermal resistance between the circulating fluid in a certain pipe and the borehole wall and $R_{i j}(i, j=1,2,3$, $4)$ is the resistance between two pipes.

Assuming a symmetric configuration of the U-tubes $R_{i j}=R_{j i}, R_{i i}=R_{j j}$ and $R_{14}=R_{12}$ and so on. Based on the line-source approximation presented by Hellström (1991) three remaining resistances can be calculated as:

$$
\begin{aligned}
& R_{11}=\frac{1}{2 \pi k_{b}}\left[\ln \left(\frac{r_{b}}{r_{p, o}}\right)-\frac{k_{b}-k}{k_{b}+k} \ln \left(\frac{r_{b}^{2}-D^{2}}{r_{b}^{2}}\right)\right]+R_{p} \\
& R_{12}=\frac{1}{2 \pi k_{b}}\left[\ln \left(\frac{r_{b}}{\sqrt{2} D}\right)-\frac{k_{b}-k}{2\left(k_{b}+k\right)} \ln \left(\frac{r_{b}^{4}+D^{4}}{r_{b}^{4}}\right)\right] \\
& R_{13}=\frac{1}{2 \pi k_{b}}\left[\ln \left(\frac{r_{b}}{2 D}\right)-\frac{k_{b}-k}{k_{b}+k} \ln \left(\frac{r_{b}^{2}+D^{2}}{r_{b}^{2}}\right)\right]
\end{aligned}
$$

where $k_{b}$ and $k$ are the thermal conductivity of the borehole and ground respectively, $r_{b}$ and $r_{p, o}$ are the radiuses of the borehole and $\mathrm{U}$-tube pipe respectively, $D$ is the distance from the U-tube pipe center to the borehole center. $R_{p}$ is the heat transfer resistance from the fluid inside the U-tube and can be calculated as:

$$
R_{p}=\frac{1}{2 \pi k_{p}} \ln \left(\frac{r_{p, o}}{r_{p, i}}\right)+\frac{1}{2 \pi r_{p} h_{f}}
$$

where $k_{p}$ is the thermal conductivity of the U-tube, subscripts $o$ and $i$ refer to the outer and inner radiuses of the U-tube pipe and $h_{f}$ is the convective heat transfer coefficient for the fluid. First part of the Equation (3) refers to the conductive resistance of the pipe and the second part to the fluid convective resistance.

Nusselt number, which is needed for the calculation of $h_{f}$, can be calculated for turbulent flow using DittusBoelter equation:

$$
N u=0.023 R e^{0.8} \operatorname{Pr}^{0.35}
$$

where $R e$ is the Reynolds number and $\operatorname{Pr}$ is the Prandtl number. Then, $h_{f}$ can be calculated as:

$$
h_{f}=\frac{k_{f} N u}{2 r_{p, i}}
$$

where $k_{f}$ is the thermal conductivity of the fluid.

The linear transformation of the Equation (1) leads to energy equilibrium equations for the fluid in individual pipes:

$$
\begin{aligned}
\pm M_{f} c_{f} \frac{d T_{f 1}}{d z}= & \frac{T_{f 1}-T_{b}}{R_{1}^{\Delta}}+\frac{T_{f 1}-T_{f 2}}{R_{12}^{\Delta}}+\frac{T_{f 1}-T_{f 3}}{R_{13}^{\Delta}} \\
& +\frac{T_{f 1}-T_{f 4}}{R_{12}^{\Delta}} \\
\pm M_{f} c_{f} \frac{d T_{f 2}}{d z}= & \frac{T_{f 2}-T_{f 1}}{R_{12}^{\Delta}}+\frac{T_{f 2}-T_{b}}{R_{1}^{\Delta}}+\frac{T_{f 2}-T_{f 3}}{R_{12}^{\Delta}} \\
& +\frac{T_{f 2}-T_{f 4}}{R_{13}^{\Delta}} \\
\pm M_{f} c_{f} \frac{d T_{f 3}}{d z}= & \frac{T_{f 3}-T_{f 1}}{R_{13}^{\Delta}}+\frac{T_{f 3}-T_{f 2}}{R_{12}^{\Delta}}+\frac{T_{f 3}-T_{b}}{R_{1}^{\Delta}} \\
& +\frac{T_{f 3}-T_{f 4}}{R_{12}^{\Delta}} \\
\pm M_{f} c_{f} \frac{d T_{f 4}}{d z}= & \frac{T_{f 4}-T_{f 1}}{R_{12}^{\Delta}}+\frac{T_{f 4}-T_{f 2}}{R_{13}^{\Delta}}+\frac{T_{f 4}-T_{f 3}}{R_{12}^{\Delta}} \\
& +\frac{T_{f 4}-T_{b}}{R_{1}^{\Delta}}
\end{aligned}
$$

where $0 \leq z \leq H$ and $H$ is the borehole depth, $M_{f}$ is the mass flow rate of the fluid, $c_{f}$ is the heat capacity of the fluid and

$$
\begin{aligned}
R_{1}^{\Delta} & =R_{11}+R_{13}+2 R_{12} \\
R_{12}^{\Delta} & =\frac{R_{11}^{2}+R_{13}^{2}+2 R_{11} R_{13}-4 R_{12}^{2}}{R_{12}} \\
R_{13}^{\Delta} & =\frac{\left(R_{11}-R_{13}\right)\left(R_{11}^{2}+R_{13}^{2}+2 R_{11} R_{13}-4 R_{12}^{2}\right)}{R_{13}^{2}+R_{11} R_{13}-2 R_{12}^{2}}
\end{aligned}
$$

The sign on the left side of Equation (6) is positive for downward flow and negative for upward flow. Two conditions are necessary to solve the equations in Equation (6): when $z=0$ the fluid temperature for the 
downward flow is equal to the inlet temperature $T_{\text {in }}$ and when $z=H$ the fluid temperature for the downward flow is equal to the fluid temperature for the upward flow. Applying these conditions, Zeng et al. (2003a; 2003b) used Laplace transform technique to solve the energy equilibrium equations in Equation (6) for the circulating fluid. As a result, the fluid temperature for the downward and upward flow in case of a single U-tube (pipes 1 and 3 or 2 and 4 in Figure 1) inside the borehole can be calculated as:

$$
\begin{aligned}
\theta_{1}(Z) & =\cosh (\beta Z)-\frac{1}{\beta S_{12}}\left[\left(\frac{S_{12}}{S_{1}}+1\right)\right. \\
& \left.-\frac{\beta S_{1} \cosh (\beta)-\sinh (\beta)}{\beta S_{1} \cosh (\beta)+\sinh (\beta)}\right] \sinh (\beta Z) \\
\theta_{2}(Z) & =\frac{\beta S_{1} \cosh (\beta)-\sinh (\beta)}{\beta S_{1} \cosh (\beta)+\sinh (\beta)} \cosh (\beta Z) \\
& +\frac{1}{\beta S_{12}}\left[1-\left(\frac{S_{12}}{S_{1}}\right.\right. \\
& \left.+1) \frac{\beta S_{1} \cosh (\beta)-\sinh (\beta)}{\beta S_{1} \cosh (\beta)+\sinh (\beta)}\right] \sinh (\beta Z)
\end{aligned}
$$

where dimensionless parameters $\Theta, Z, S_{1}, S_{12}$ and $\beta$ are defined as:

$$
\begin{aligned}
\theta & =\frac{T(z)-T_{b}}{T_{\text {in }}-T_{b}} \\
Z & =\frac{Z}{H} \\
S_{1} & =\frac{M_{f} c_{f}}{H}\left(R_{11}+R_{13}\right) \\
S_{12} & =\frac{M_{f} c_{f}}{H} \frac{R_{11}^{2}-R_{13}^{2}}{R_{13}} \\
\beta & =\sqrt{\frac{1}{S_{1}^{2}}+\frac{2}{S_{1} S_{12}}}
\end{aligned}
$$

The heat transfer rate per unit length into or from the ground can be calculated as:

$$
q=\frac{\left(T_{\text {in }}-T_{\text {out }}\right) M_{f} c_{f}}{H}
$$

In case of a double U-tube configuration inside borehole two cases for a parallel connection can be found. The fluid can flow through pipes 1 and 3 and pipes 2 and 4 $(1-3,2-4)$ or through pipes 1 and 2 and pipes 3 and 4 $(1-2,3-4)$. In both cases, Equation (7) can be used to calculate the fluid temperature but the dimensionless parameters $S_{1}$ and $S_{12}$ are defined as

$$
\begin{aligned}
S_{1} & =\frac{M_{f} c_{f}}{H} R_{1}^{\Delta} \\
S_{12} & =\frac{M_{f} c_{f}}{H} \frac{R_{12}^{\Delta} R_{13}^{\Delta}}{R_{12}^{\Delta}+R_{13}^{\Delta}}
\end{aligned}
$$

when the flow is $(1-3,2-4)$, and as

$$
\begin{gathered}
S_{1}=\frac{M_{f} c_{f}}{H} R_{1}^{\Delta} \\
S_{12}=\frac{M_{f} c_{f}}{H} \frac{R_{12}^{\Delta}}{2}
\end{gathered}
$$

when the flow is $(1-2,3-4)$.

\subsection{Heat Transfer Outside Borehole}

Eskilson (1987) presented a numerical method to calculate g-functions that represent the dimensionless temperature response in the ground outside the boreholes by also taking into account the heat flow along the borehole depth. This was a major advancement from the previous infinite line-source model and cylindrical source model. However, the gfunctions have to be calculated numerically for different borehole field configurations and is therefore timeconsuming to implement in simulation programs. Based on Eskilson's (1987) model, Zeng et al. (2002) proposed an analytical method for calculating the ground temperature response. This finite line-source model was later modified by Lamarche and Beauchamp (2007) to faster calculate the ground temperature response using the integral mean borehole temperature. This model to calculate ground temperature response at time $t$ and distance $r$ from the borehole is shown in Equation (9) as presented by Marcotte et al. (2010).

$$
\begin{aligned}
\Delta T(r, t) & =\frac{q}{2 \pi k_{g}}\left(\int_{B}^{\sqrt{B^{2}+1}} \frac{\operatorname{erfc}(\omega z)}{\sqrt{z^{2}-B^{2}}} d z-D_{A}\right. \\
& \left.-\int_{\sqrt{B^{2}+1}}^{\sqrt{B^{2}+4}} \frac{\operatorname{erfc}(\omega z)}{\sqrt{z^{2}-B^{2}}} d z-D_{B}\right)
\end{aligned}
$$

Parameters $B$ and $\omega$ in Equation (9) are defined as follows $B=r / H, \omega=\frac{H}{2 \sqrt{a t}}$ and $D_{A}$ and $D_{B}$ are given by:

$$
\begin{aligned}
D_{A} & =\sqrt{B^{2}+1} \operatorname{erfc}\left(\omega \sqrt{B^{2}+1}\right)-B \operatorname{erfc}(\omega B) \\
& -\frac{e^{-\omega^{2}\left(B^{2}+1\right)}-e^{-\omega^{2} B^{2}}}{\omega \sqrt{\pi}}
\end{aligned}
$$

and

$$
\begin{aligned}
D_{B} & =\sqrt{B^{2}+1} \operatorname{erfc}\left(\omega \sqrt{B^{2}+1}\right) \\
& -0.5[\operatorname{Berfc}(\omega B) \\
& \left.+\sqrt{B^{2}+4} \operatorname{erfc}\left(\omega \sqrt{B^{2}+4}\right)\right] \\
& -\frac{e^{-\omega^{2}\left(B^{2}+1\right)}-0.5\left(e^{-\omega^{2} B^{2}}+e^{-\omega^{2}\left(B^{2}+4\right)}\right)}{\omega \sqrt{\pi}}
\end{aligned}
$$

Marcotte and Pasquier (2008) applied fast Fourier transformation (FFT) to efficiently calculate the hourly ground temperature response with varying loads by applying the superposition principle in time (Yavuzturk, 1999). When the unit response calculated with Equation (9) $(q=1)$ and the incremental load is known at each time step, the ground temperature can be calculated by evaluating the convolution product of these two (Marcotte and Pasquier, 2008):

$$
\Delta T(r, t)=F F T^{-1}\left(F F T\left(q_{i}\right) F F T(f)\right)
$$


where $\mathrm{FFT}^{-1}$ is the inverse-FFT, $q_{i}$ is the incremental load and $f$ is the unit response calculated with Equation (9).

As can be seen from Equation (9), the calculation of the unit temperature response in the ground requires solving the integrals at each time step which can be time consuming for longer simulation periods. For 20-year simulation, Equation (9) would need to be solved $20 \times 8760=175,200$ times. However, Marcotte and Pasquier (2008) presented a faster method to calculate the unit temperature response for long simulation periods. In their method, the Equation (9) is only solved at certain time points that follow geometric progression and the solutions for all the other time points are obtained using cubic spline interpolant. Equation (9) is solved at times $1-48,50,54,62,78,110,174,302$, and so on up to, and including, the last time point. Marcotte and Pasquier (2008) reported $0.0007{ }^{\circ} \mathrm{C}$ maximum difference between the calculated and interpolated unit temperature response showing very good accuracy of the interpolation method.

\subsection{Error Analysis}

Mean Absolute Percentage Error (MAPE), Mean Absolute Error (MAE) and Root Mean Squared Error (RMSE) were used to analyze the error between the measured experimental validation data and the simulation model:

$$
\begin{aligned}
M A P E & =\left[\frac{1}{N} \sum_{t=1}^{N}\left(\frac{|x(t)-y(t)|}{y(t)}\right)\right] \cdot 100 \% \\
M A E & =\frac{1}{N} \sum_{t=1}^{N}(|x(t)-y(t)|) \\
R M S E & =\sqrt{\frac{1}{N} \sum_{t=1}^{N}(x(t)-y(t))^{2}}
\end{aligned}
$$

where $x$ and $y$ are the measured value and the output of the simulation model at time $t$ respectively. Mean errors between the measured and simulated values are also reported to estimate the bias.

\section{Simulation Model}

The finite line-source model for the heat transfer outside the borehole and the quasi-3D model for the heat transfer inside the borehole presented in Section 2 were implemented in Matlab $^{\circledR}$ environment. Parameters for the simulation model are listed in Table 1. Measured input was the inlet temperature $\left({ }^{\circ} \mathrm{C}\right)$ or the heating/cooling load (W).

Water was used as default heat transfer fluid in the simulation model, but fluid properties can be easily changed if some other fluid than water is used. The heat capacity and dynamic viscosity of water were taken from tabular values based on water temperature rounded
Table 1. Parameters for the simulation model.

\begin{tabular}{ll}
\hline Parameter & Unit \\
\hline Number of boreholes & - \\
Distance between boreholes & $\mathrm{m}$ \\
Borehole depth, $H$ & $\mathrm{~m}$ \\
Borehole radius, $r_{b}$ & $\mathrm{~m}$ \\
Ground thermal conductivity, $k_{g}$ & $\mathrm{~W} / \mathrm{m} \mathrm{K}$ \\
Ground thermal diffusivity, $\alpha$ & $\mathrm{m}^{2} / \mathrm{s}$ \\
Initial ground temperature, $T_{0}$ & ${ }^{\circ} \mathrm{C}$ \\
Grout thermal conductivity, $k_{b}$ & $\mathrm{~W} / \mathrm{m} \mathrm{K}$ \\
U-tube configuration & - \\
U-tube thermal conductivity, $k_{p}$ & $\mathrm{~W} / \mathrm{m} \mathrm{K}$ \\
U-tube inner radius, $r_{p, i}$ & $\mathrm{~m}$ \\
U-tube outer radius, $r_{p, o}$ & $\mathrm{~m}$ \\
$\begin{array}{l}\text { Distance from U-tube center to borehole } \\
\text { center, } D\end{array}$ & $\mathrm{~m}$ \\
Fluid mass flow, $M_{f}$ & $\mathrm{~kg} / \mathrm{s}$ \\
\hline
\end{tabular}

to the nearest integer. The thermal conductivity of the water was calculated as (Ramires et al., 1995):

$$
\begin{aligned}
k_{f} & =0.6065\left(-1.48445+4.12292\left(\frac{273.15+T_{\text {in }}}{298.15}\right)\right. \\
& \left.-1.63866\left(\frac{273.15+T_{\text {in }}}{298.15}\right)^{2}\right)
\end{aligned}
$$

The simulation model can be used to calculate the outlet and ground temperature of the borehole field based on the known heating/cooling load or inlet temperature. The spatial superposition principle was applied to calculate the ground temperature response of the borehole field (Eskilson, 1987; Yavuzturk, 1999; Zeng et al., 2002). This means that the ground temperature response on a certain borehole wall is calculated by taking into account the effect of all the other boreholes. This requires solving Equation (9) for every distance between individual boreholes at each time instance. By default, for the ease and speed of computation, the simulation model is set up for a square or rectangular configuration of the borehole field where every borehole is at equal distance from each other. This allows taking advantage of the symmetry of some boreholes reducing the amount of calculations. However, the advantage of the analytical approach is that any regular or irregular borehole field configuration can be easily simulated with the model by providing borehole coordinates.

Based on the borehole field configuration, the mean unit temperature response of the ground at borehole wall for the whole borehole field is calculated with Equation (9) applying spatial superposition. For faster calculation, the cubic spline interpolation method presented in Section 2.2 is also applied. If the heating/cooling load is known, Equation (10) is used to calculate the hourly ground temperature response. Integrals are solved using quadgk function from Matlab $^{\circledR}$. Then an iterative search is executed to find the 
proper inlet and outlet temperatures applying Equations (7) and (8). If the inlet temperature is known, an optimization algorithm fminbnd from $\mathrm{Matlab}^{\circledR}$ is used to find the proper heating rate and outlet temperature applying Equations (10), (7), and (8). The flow chart in Figure 2 presents the principle of the calculation procedure.

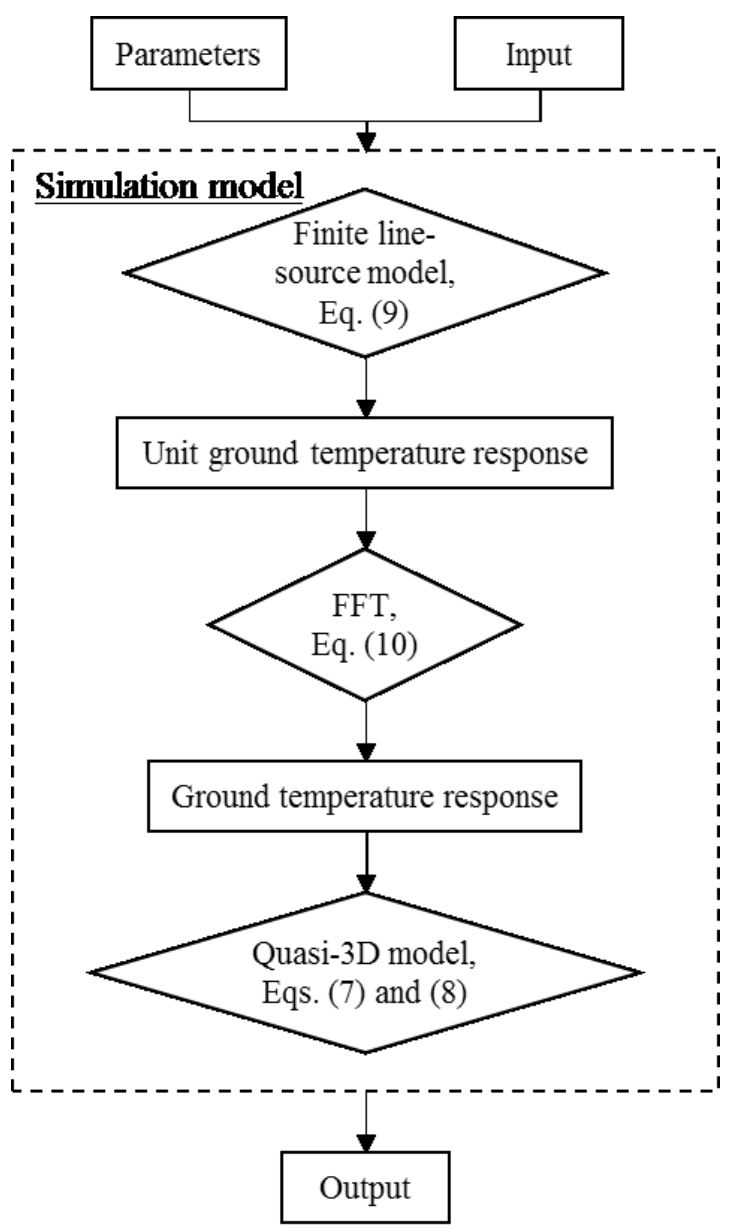

Figure 2. The principle of the calculation procedure for the BHE field.

\section{Validation of the Modelling Methods}

As there are no available experimental data sets for GHEs with multiple boreholes, two laboratory scale experimental data sets for single borehole systems were used for the validation of the modelling method. Data set 1 came from Shirazi and Bernier (2014), where the experimental apparatus was a small-scale laboratory tank with a single U-tube borehole. Data consisted of the measured ground temperature, supply and return temperature and flow rate recorded in ten second intervals for a 73-hour heat injection period. Data set 2 came from Beier et al. (2011), where the experimental facility was a large sandbox with a single U-tube borehole. Data set comprised minutely recorded values for the ground temperature, supply and return temperature and flow rate for 52 hours with constant
Table 2. Parameter values for data sets 1 and 2 .

\begin{tabular}{llll}
\hline Parameter & Data set 1 & Data set 2 & Unit \\
\hline$H$ & 1.23 & 18.3 & $\mathrm{~m}$ \\
$r_{b}$ & 0.038 & 0.064 & $\mathrm{~m}$ \\
$k_{g}$ & 0.29 & 2.82 & $\mathrm{~W} / \mathrm{m} \mathrm{K}$ \\
$\alpha$ & $2.292 \times 10^{-7}$ & $8.8125 \times 10^{-7}$ & $\mathrm{~m}^{2} / \mathrm{s}$ \\
$T_{0}$ & 23.5 & 22 & ${ }^{\circ} \mathrm{C}$ \\
$k_{b}$ & 0.35 & 0.73 & $\mathrm{~W} / \mathrm{m} \mathrm{K}$ \\
$k_{p}$ & 401 & 0.39 & $\mathrm{~W} / \mathrm{m} \mathrm{K}$ \\
$r_{p, i}$ & 0.00395 & 0.0137 & $\mathrm{~m}$ \\
$r_{p, o}$ & 0.00475 & 0.0167 & $\mathrm{~m}$ \\
$D$ & 0.014275 & 0.0265 & $\mathrm{~m}$ \\
\hline
\end{tabular}

heat input. The applied model parameters for both data sets are presented in Table 2. For data set 2, $\alpha$ was calculated using the volumetric heat capacity of $3.2 \times 10^{6}$ $\mathrm{J} / \mathrm{K} \mathrm{m}^{3}$ as provided by Beier (2014).

First, the finite line-source model (Equation (9)) was tested to see if the model output follows the measured ground temperature. For data set 1, the ground temperature at borehole wall was calculated as a mean temperature of the sixteen temperature measurements provided at the borehole wall. The same was done with the data set 2 using four measured temperatures at the borehole wall. Equation (8) was used to calculate the

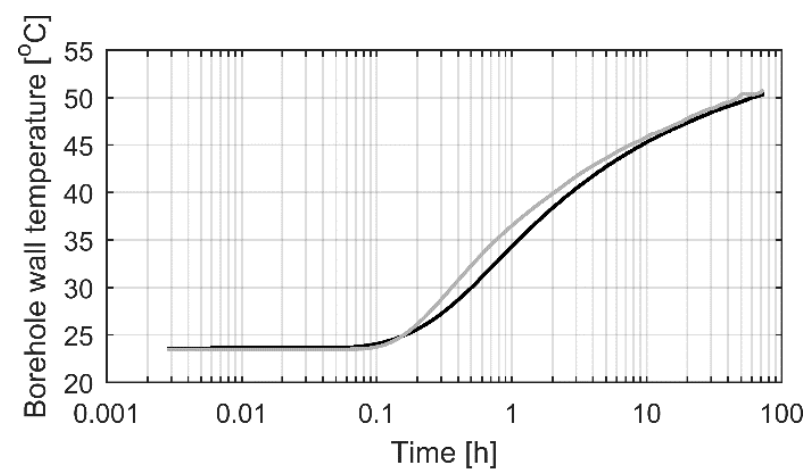

(a)

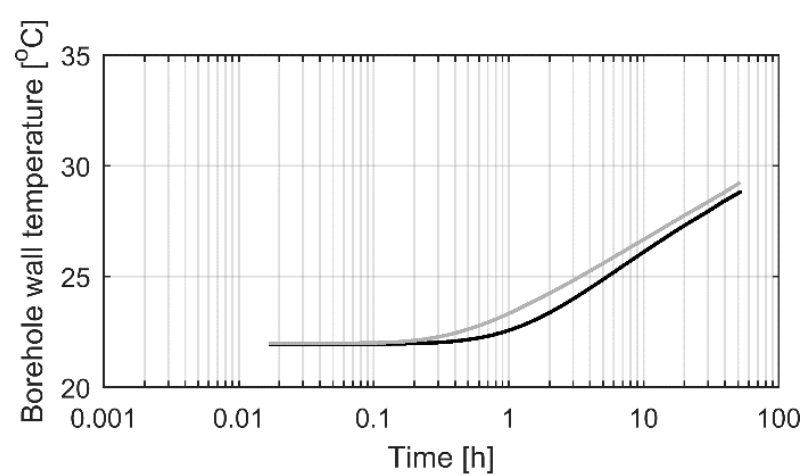

(b)

Figure 3. Modelling results on borehole wall temperature with (a) data set 1 and (b) data set 2. Black line is the mean borehole wall temperature calculated from the measured experimental data and grey line is the modelled borehole wall temperature. 
Table 3. Modelling error for data sets 1 and 2 .

\begin{tabular}{lll}
\hline & Data set 1 & Data set 2 \\
\hline Borehole wall temperature & & \\
MAPE $(\%)$ & 1.16 & 1.81 \\
MAE $\left({ }^{\circ} \mathrm{C}\right)$ & 0.53 & 0.49 \\
RMSE $\left({ }^{\circ} \mathrm{C}\right)$ & 0.61 & 0.50 \\
Outlet temperature & & \\
MAPE $(\%)$ & 0.27 & 0.78 \\
MAE $\left({ }^{\circ} \mathrm{C}\right)$ & 0.17 & 0.28 \\
RMSE $\left({ }^{\circ} \mathrm{C}\right)$ & 0.35 & 0.29 \\
\hline
\end{tabular}

heating rate per unit length and then Equations (9) and (10) were applied to calculate the ground temperature response. The specific heat of water was assumed as $4200 \mathrm{~J} / \mathrm{kg} \mathrm{K}$. Results are presented as a semi-log plot in Figure 3 and the modelling errors are presented in Table 3.

Mean errors for data sets 1 and 2 were $-0.53{ }^{\circ} \mathrm{C}$ and $0.49{ }^{\circ} \mathrm{C}$ respectively, showing that the model slightly overestimates the ground temperature in both cases. This could be expected for the short simulation period that both data sets cover and it can be seen in Figure 3 that the error decreases in longer times. Maximum absolute errors for data sets 1 and 2 were $2.41{ }^{\circ} \mathrm{C}$ and $0.88{ }^{\circ} \mathrm{C}$ respectively. For both data sets, the maximum errors were related to early times in the modelling period. It is well known that finite line-source model is not accurate to model short term performance as the heat capacities inside the borehole are neglected by the model (Yang et al., 2010). As Eskilson (1987) presented, finite line-source model is valid approximately after time $5 r_{b}{ }^{2} / \alpha$, which for data sets 1 and 2 were 8.8 and 6.5 hours respectively. Errors for data set 1 reach maximum around 0.5 hours and rapidly decrease after that and reaching absolute errors below $0.8{ }^{\circ} \mathrm{C}$ after 8.8 hours. For data set 2 , the maximum errors occur around two hours and then slowly decrease. After 6.5 hours, absolute errors were below $0.7^{\circ} \mathrm{C}$.

Next, the modelled borehole wall temperature and measured inlet temperature and flow rate were used to calculate the outlet temperature applying the quasi-3D model (Equation (7)). As the inlet temperature was almost constant for data set 1 , the dynamic viscosity and thermal conductivity for the water were assumed constants as 0.0004 Pas and $0.66 \mathrm{~W} / \mathrm{m} \mathrm{K}$ respectively. Results are presented as a semi-log plot in Figure 4 and the modelling errors can be found in Table 3.

For data set 1 , the mean error was $0.16^{\circ} \mathrm{C}$. Although slightly underestimating, showing very good accuracy. For data set 2 , the mean error was $-0.28^{\circ} \mathrm{C}$, showing that there the model slightly overestimates the outlet temperature, although the modelling error decreases in longer times. Maximum absolute errors for data sets 1 and 2 were $30.35{ }^{\circ} \mathrm{C}$ and $1.11{ }^{\circ} \mathrm{C}$ respectively. Maximum errors for data set 1 were relatively big, but these maximum errors occurred only very early in the

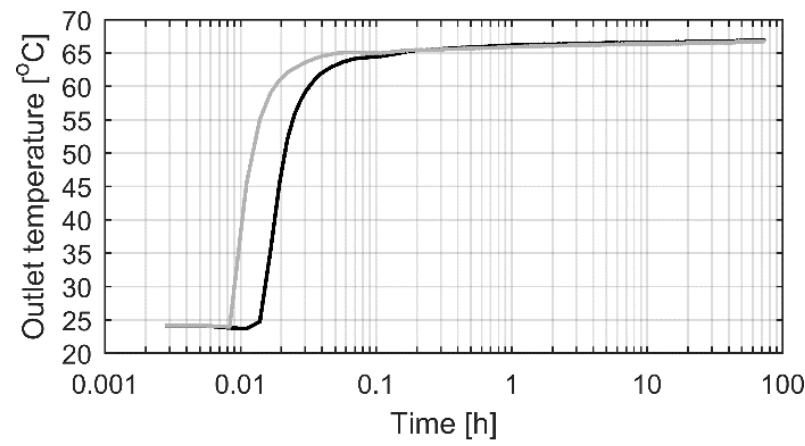

(a)

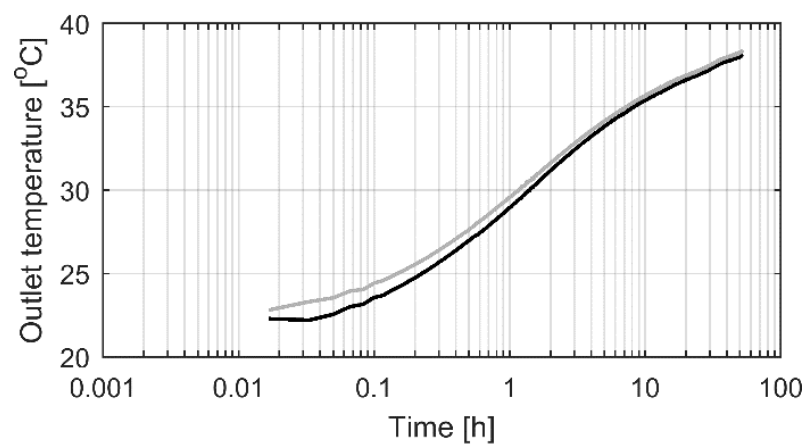

(b)

Figure 4. Modelling results on outlet temperature with (a) data set 1 and (b) data set 2. Black line is the measured outlet temperature from the experimental data and grey line is the modelled outlet temperature.

modelling period. Inlet temperature was increased rapidly in data set 1 at the start of the test and as the quasi-3D model neglects the heat capacity inside the borehole (Zeng et al., 2003b) the model overestimated the outlet temperature. However, after 9 minutes, which is much lower than the calculated validity time 8.8 hours, absolute errors were below $0.33{ }^{\circ} \mathrm{C}$. For data set 2 , absolute errors were below $0.33^{\circ} \mathrm{C}$ after 6.5 hours.

The above results with two experimental data sets showed that the modelling errors were low. Taking into account the errors related to measurements, heating rate, thermal conductivities and heat capacities (Shirazi and Bernier, 2014; Li and Lai, 2013; Beier et al., 2011), it can be concluded that the selected methods for the simulation model can be applied to accurately model long-term borehole ground and fluid temperatures.

\section{Conclusions}

In this paper, simulation model for BHEs was developed applying finite line-source and quasi-3D models. For faster calculation time in case of time varying loads and longer simulation periods FFT technique and a cubic spline interpolation method were utilized. The simulation model was validated with two different laboratory scale experimental data sets. Results showed low modelling error with experimental data validating the correct performance of the simulation model. 
The developed simulation model can be used for a long-term modelling of BHE fields consisting of multiple boreholes. It can also be applied for system level simulations by including heat pumps and different heat sources (e.g. solar collectors). Some shortcomings of the developed simulation model should be addressed in future work for wider applicability. These include adding the ability to take into account the borehole inclination and the efficient calculation of borehole fields with series connections.

\section{References}

G. Alva, Y. Lin, and G. Fang. An overview of thermal energy storage systems. Energy, 144:341-378, 2018. doi:10.1016/j.energy.2017.12.037.

R. A. Beier. Transient heat transfer in a U-tube borehole heat exchanger. Applied Thermal Engineering, 62(1):256-266, 2014. doi:10.1016/j.applthermaleng.2013.09.014.

R. A. Beier, M. D. Smith, and J. D. Spitler. Reference data sets for vertical borehole ground heat exchanger models and thermal response test analysis. Geothermics, 40(1):79-85, 2011. doi:10.1016/j.geothermics.2010.12.007.

P. Eskilson. Thermal analysis of heat extraction boreholes. PhD Thesis, University of Lund, 1987.

G. Hellström. Ground heat storage: thermal analyses of duct storage system. PhD Thesis, University of Lund, 1991.

S. Koohi-Fayegh and M. A. Rosen. A review of the modelling of thermally interacting multiple boreholes. Sustainability, 5(6):2519-2536, 2013. doi:10.3390/su5062519.

L. Lamarche and B. Beauchamp. A new contribution to the finite line-source model for geothermal boreholes. Energy and Buildings, 39(2):188-198, 2007. doi:10.1016/j.enbuild.2006.06.003.

M. Li and A. C. K. Lai. Analytical model for short-time responses of ground heat exchangers with U-shaped tubes: Model development and validation. Applied Energy, 104:510-516, 2013. doi:10.1016/j.apenergy.2012.10.057.

M. Li and A. C. K. Lai. Review of analytical models for heat transfer by vertical ground heat exchangers (GHEs): A perspective of time and space scales. Applied Energy, 151:178-191, 2015. doi:10.1016/j.apenergy.2015.04.070.

J. W. Lund and T. L. Boyd. Direct utilization of geothermal energy 2015 worldwide review. Geothermics, 60:66-93, 2016. doi:10.1016/j.geothermics.2015.11.004.

D. Marcotte and P. Pasquier. Fast fluid and ground temperature computation for geothermal ground-loop heat exchanger systems. Geothermics, 37(6):651-665, 2008. doi:10.1016/j.geothermics.2008.08.003.

D. Marcotte, P. Pasquier, F. Sheriff, and M. Bernier. The importance of axial effects for borehole design of geothermal heat-pump systems. Renewable Energy, 35(4):763-770, 2010. doi:10.1016/j.renene.2009.09.015.

M. L. V. Ramires, C. A. Nieto de Castro, Y. Nagasaka, A. Nagashima, M. J. Assael, and W. A. Wakeham. Standard reference data for the thermal conductivity of water. Journal of Physical and Chemical Reference Data, 24:1377-1381, 1995. doi:10.1063/1.555963.
A. S. Shirazi and M. Bernier. A small-scale experimental apparatus to study heat transfer in the vicinity of geothermal boreholes. HVAC\&R Research, 20(7):819-827, 2014. doi:10.1080/10789669.2014.939553.

J. Xu, R. Z. Wang, and Y. Li. A review of available technologies for seasonal thermal energy storage. Solar Energy, 103:610-638, 2014. doi:10.1016/j.solener.2013.06.006.

H. Yang, P. Cui, and Z. Fang. Vertical-borehole groundcoupled heat pumps: A review of models and systems. Applied Energy, 87(1):16-27, 2010. doi:10.1016/j.apenergy.2009.04.038.

C. Yavuzturk. Modelling of vertical ground loop heat exchangers for ground source heat pump systems. Master's Thesis, Technical University of Berlin, 1999.

H. Y. Zeng, N. R. Diao, and Z. H. Fang. A finite line-source model for boreholes in geothermal heat exchangers. Heat Transfer-Asian Research, 31(7):558-567, 2002. doi:10.1002/htj.10057.

H. Zeng, N. Diao, and Z. Fang. Efficiency of vertical geothermal heat exchangers in the ground source heat pump system. Journal of Thermal Science, 12(1):77-81, $2003 \mathrm{a}$. doi:10.1007/s11630-003-0012-1.

H. Zeng, N. Diao, and Z. Fang. Heat transfer analysis of boreholes in vertical ground heat exchangers. International Journal of Heat and Mass Transfer, 46(23):4467-4481, 2003b. doi:10.1016/S0017-9310(03)00270-9. 